
\title{
The receptor protein tyrosine phosphatase PTPRJ negatively modulates the CD98hc oncoprotein in lung cancer cells
}

\author{
Sabrina D'Agostino ${ }^{1}$, Delia Lanzillotta ${ }^{1}$, Mariaconcetta Varano${ }^{1}$, Cirino Botta ${ }^{1}$, \\ Antonio Baldrini ${ }^{1}$, Anna Bilotta ${ }^{1}$, Stefania Scalise ${ }^{1}$, Vincenzo Dattilo ${ }^{2}$, Rosario \\ Amato $^{2}$, Eugenio Gaudio ${ }^{1,3}$, Francesco Paduano ${ }^{1,4}$, Camillo Palmieri ${ }^{1}$, Rodolfo \\ Iuliano ${ }^{1}$, Nicola Perrotti ${ }^{2}$, Cesare Indiveri ${ }^{5}$, Alfredo Fusco $^{6}$, Marco Gaspari ${ }^{1}$ and \\ Francesco Trapasso ${ }^{1}$ \\ ${ }^{1}$ Dipartimento di Medicina Sperimentale e Clinica, University Magna Græcia, Campus "S. Venuta", Catanzaro, Italy \\ 2 Dipartimento di Scienze della Salute, University Magna Græcia, Campus "S. Venuta", Catanzaro, Italy \\ ${ }^{3}$ Lymphoma and Genomics Research Program, IOR Institute of Oncology Research, Bellinzona, Switzerland \\ ${ }^{4}$ Tecnologica Research Institute, Biomedical Section, Crotone, Italy \\ ${ }^{5}$ Dipartimento di Biologia, Ecologia, Scienze Della Terra (DiBEST), Unit of Biochemistry and Molecular Biotechnology, \\ University of Calabria, Arcavacata di Rende, Italy \\ ${ }^{6}$ Istituto di Endocrinologia e Oncologia Sperimentale, CNR c/o Dipartimento di Medicina Molecolare e Biotecnologie Mediche, \\ University "Federico II" of Napoli, Napoli, Italy \\ Correspondence to: Francesco Trapasso, email: trapasso@unicz.it \\ Keywords: protein tyrosine phosphatase; PTPRJ; CD98hc; proteasomal degradation; lung cancer \\ Received: October 05, $2017 \quad$ Accepted: March 24, $2018 \quad$ Published: May 04, 2018 \\ Copyright: D'Agostino et al. This is an open-access article distributed under the terms of the Creative Commons Attribution License \\ 3.0 (CC BY 3.0), which permits unrestricted use, distribution, and reproduction in any medium, provided the original author and \\ source are credited.
}

\section{ABSTRACT}

PTPRJ, a receptor protein tyrosine phosphatase strongly downregulated in human cancer, displays tumor suppressor activity by negatively modulating several proteins involved in proliferating signals. Here, through a proteomic-based approach, we identified a list of potential PTPRJ-interacting proteins and among them we focused on CD98hc, a type II glycosylated integral membrane protein encoded by SLC3A2, corresponding to the heavy chain of a heterodimeric transmembrane aminoacid transporter, including LAT1. CD98hc is widely overexpressed in several types of cancers and contributes to the process of tumorigenesis by interfering with cell proliferation, adhesion, and migration. We first validated PTPRJ-CD98hc interaction, then demonstrated that PTPRJ overexpression dramatically reduces CD98hc protein levels in A549 lung cancer cells. In addition, following to the treatment of PTPRJtransduced cells with MG132, a proteasome inhibitor, CD98hc levels did not decrease compared to controls, indicating that PTPRJ is involved in the regulation of CD98hc proteasomal degradation. Moreover, PTPRJ overexpression combined with CD98hc silencing consistently reduced cell proliferation and triggered apoptosis of lung cancer cells. Interestingly, by interrogating the can Evolve database, we observed an inverse correlation between PTPRJ and SLC3A2 gene expression. Indeed, the non-small cell lung cancers (NSCLCS) of patients showing a short survival rate express the lowest and the highest levels of PTPRJ and SLC3A2, respectively. Therefore, the results reported here contribute to shed lights on PTPRJ signaling in cancer cells: moreover, our findings also support the development of a novel anticancer therapeutic approach by targeting the pathway of PTPRJ that is usually downregulated in highly malignant human neoplasias. 


\section{INTRODUCTION}

PTPRJ, a member of the protein tyrosine phosphatases family with tumor suppressor activity, is downregulated in several cancer tissues and cell lines and its restoration blocks their proliferation [1-3]. Other than promoter hypermethylation [4] and loss of heterozygosity (LOH), observed in colon, lung, mammary, and thyroid tumors [5-7], we have also previously shown that PTPRJ is a target of miR-328. Indeed, miR-328 expression leads to PTPRJ downregulation through increasing cell proliferation of cancer cell lines such as HeLa and SKBr3 [8]. An inverse correlation between miR-328 and PTPRJ mRNA levels has also been assessed in hepatocellular carcinoma, where PTPRJ expression negatively correlates with the progression of this malignancy [9]. However, even though specific Ptprj polymorphic alleles predispose to colon cancer [5], no spontaneous tumors have been described in $\mathrm{Ptprj}^{-/-}$mice [10].

Our group also demonstrated that virus-mediated PTPRJ overexpression is effective in preclinical models of both thyroid and pancreatic cancer [11, 12], suggesting that PTPRJ is a proof-of-principle therapeutic gene. This assumption was supported not only by the antiproliferative effects obtained through PTPRJ stimulation by a monoclonal antibody [13] but also by the discovery of synthetic PTPRJ agonist peptides able to reduce the extent of MAPK phosphorylation and, conversely, to increase cell cycle inhibitor p27 $7^{\text {Kip1 }}$ protein levels; these PTPRJ agonist peptides also reduce both cancer cell proliferation and tubulogenesis as well as trigger apoptosis of cancer cells $[14,15]$. Nowadays, two PTPRJ biological ligands have been identified: heparansulfate proteoglycan Syndecan-2 (S2ED) and Thrombospondin-1; S2ED-bound PTPRJ mediates cell adhesion by modulating $\beta 1$ integrinmediated adhesion and cytoskeletal organization while TSP1 binding increases PTPRJ activity $[16,17]$.

The biochemical pathways negatively regulated by PTPRJ have been only partly clarified; several studies report an inhibitory effect of PTPRJ on several key factors of the mitogenic signaling; in fact, PTPRJ dephosphorylates several receptor tyrosine kinases such as PDGFR [18], HGFR [19], RET [20], EGFR [21], and VEGFR [22] as well as downstream cytosolic transducers such as MAPK [23], thus inhibiting the mitogenic signals driven by them.

Here, in the attempt to further shed lights on the PTPRJ protein network and its role in cancer, we identified several novel putative candidate PTPRJ protein partners by using a proteomic-based approach. Among the listed proteins, we focused on CD98hc, a protein encoded by the SLC3A2 gene. We first demonstrated PTPRJ-CD98hc association, then that PTPRJ overexpression leads to CD98hc decreased protein levels through a proteasomaldependent degradation pathway apparently resulting in a reduced extent of both cell proliferation and migration.
Moreover, PTPRJ and CD98hc inverse correlation, assessed by interrogating canEvolve database in a large number of lung cancer patients, not only proposes these proteins as candidate biomarkers of tumor aggressiveness but also encourages the development of novel targeted therapies for the treatment of cancer.

\section{RESULTS}

\section{Identification and validation of CD98hc as a PTPRJ protein partner}

To isolate novel PTPRJ-interacting proteins, a recombinant adenovirus, coding for a histidine sixtagged PTPRJ, was used to infect recipient A549 cells as described [14]. Briefly, seventy-two hours after infection, A549-transduced cells were lysed and cell membranes enriched to maximize the purification of mature integral proteins. Recombinant PTPRJ-His6 protein along with its potentially interacting proteins were isolated from membrane extracts by using poly(His)-avid magnetic beads and processed by mass spectrometry (Figure 1). A large number of proteins were identified (699), as listed in Supplementary Table 1. Among them, 47 proteins were significantly enriched in the PTPRJ-His6 sample ( $p$-value $<0.01$, fold change $>2$ ). These proteins are listed in Table 1, whereas their Gene Ontology (GO) enrichment analysis is reported in Supplementary Table 2. Among the candidate PTPRJ-binding proteins, we focused on CD98hc.

Several findings prompted us to investigate in further detail the PTPRJ-CD98hc interaction. CD98hc heterodimerize with different light chains, thus forming amino-acidic transporters in cell membranes [24]. CD98hc constitutive deletion in mice results in early embryonic death [25], while CD98hc overexpression induced tumorigenesis in the gastrointestinal epithelium by stimulating cell proliferation [26]. Moreover, CD98hc overexpression, widely occurring in human cancer, correlates with dismal prognosis [27, 28]. Although the exact contribution of CD98hc to tumorigenesis is still not fully understood, it has been shown that it is involved in cell proliferation by mTOR pathway activation through the intracellular amino-acids transport [29]; recently, it has been reported that CD98hc cytoplasmatic domain also induces proliferation of renal epithelial cells by activating Erk and p38 MAPK signaling [30]. On the other hand, CD98hc/ $\beta$-integrin interaction was shown to be important in modulating cell spreading, migration [31], transformation [32], and survival [33].

First, we validated the interaction between recombinant His6-tagged PTPRJ protein and endogenous CD98hc in A549 lung cancer cells by coimmunoprecipitation experiments; no CD98hc protein was observed in the same assay performed with the PTPRJ protein used as a control (Figure 2A). Next, 
we also demonstrated that endogenous CD98hc coimmunoprecipitated ectopic PTPRJ protein overexpressed in A549 cells twenty-four hours after infection with a recombinant adenovirus carrying a wild-type PTPRJ cDNA at MOI30 (Figure 2B).

Finally, to investigate PTPRJ and CD98hc subcellular localization, A549 cells were transduced with Ad PTPRJ at MOI30; twenty-four hours later, both proteins clearly colocalized at the plasma membrane level (Figure 2C).

\section{PTPRJ overexpression negatively modulates CD98hc tyrosine-phosphorylation and decreases its protein levels}

Since PTPRJ interacts with CD98hc, based on the intrinsic biochemical activity of this protein tyrosine phosphatase, we investigated CD98hc protein phosphorylation status. Following to PTPRJ overexpression in A549 cells, CD98hc tyrosinephosphorylation extent and CD98hc protein levels were investigated. A549 cells were infected at MOI50 with Ad PTPRJ. Forty-eight hours later, we observed a highly significant reduction of CD98hc tyrosinephosphorylation (Figure 3A). Conversely, CD98hc tyrosine-phosphorylation status was unchanged either in untreated or in Ad GFP-infected A549 cells. Interestingly, we noticed that CD98hc protein levels were strongly affected by PTPRJ overexpression compared to mockinfected cells (Figure 3B).

To confirm CD98hc downregulation following to PTPRJ overexpression, forty-eight hours after infection with Ad PTPRJ at MOI50, A549 cells were also investigated by immunofluorescence through confocal microscopy. Results, reported in Figure 3C, show a dramatic CD98hc decrease staining at plasma membrane level in cells showing the highest PTPRJ overexpression.

\section{PTPRJ induces CD98hc ubiquitin-mediated proteasome-dependent degradation}

To better understand the mechanisms of CD98hc protein downregulation in PTPRJ-overexpressing A549 cancer cells, we first evaluated CD98hc mRNA expression by real time-PCR. As shown in Figure 4A, no changes have been reported in SLC3A2 transcript in PTPRJoverexpressing cells compared to controls, thus suggesting that post-translational modifications could account for CD98hc protein downregulation.

To this purpose, we investigated the CD98hc ubiquitylation status following to PTPRJ overexpression. As shown in Figure 4B, PTPRJ induced ubiquitylation compared to control. To determine whether PTPRJ promotes CD98hc degradation, A549 cells infected

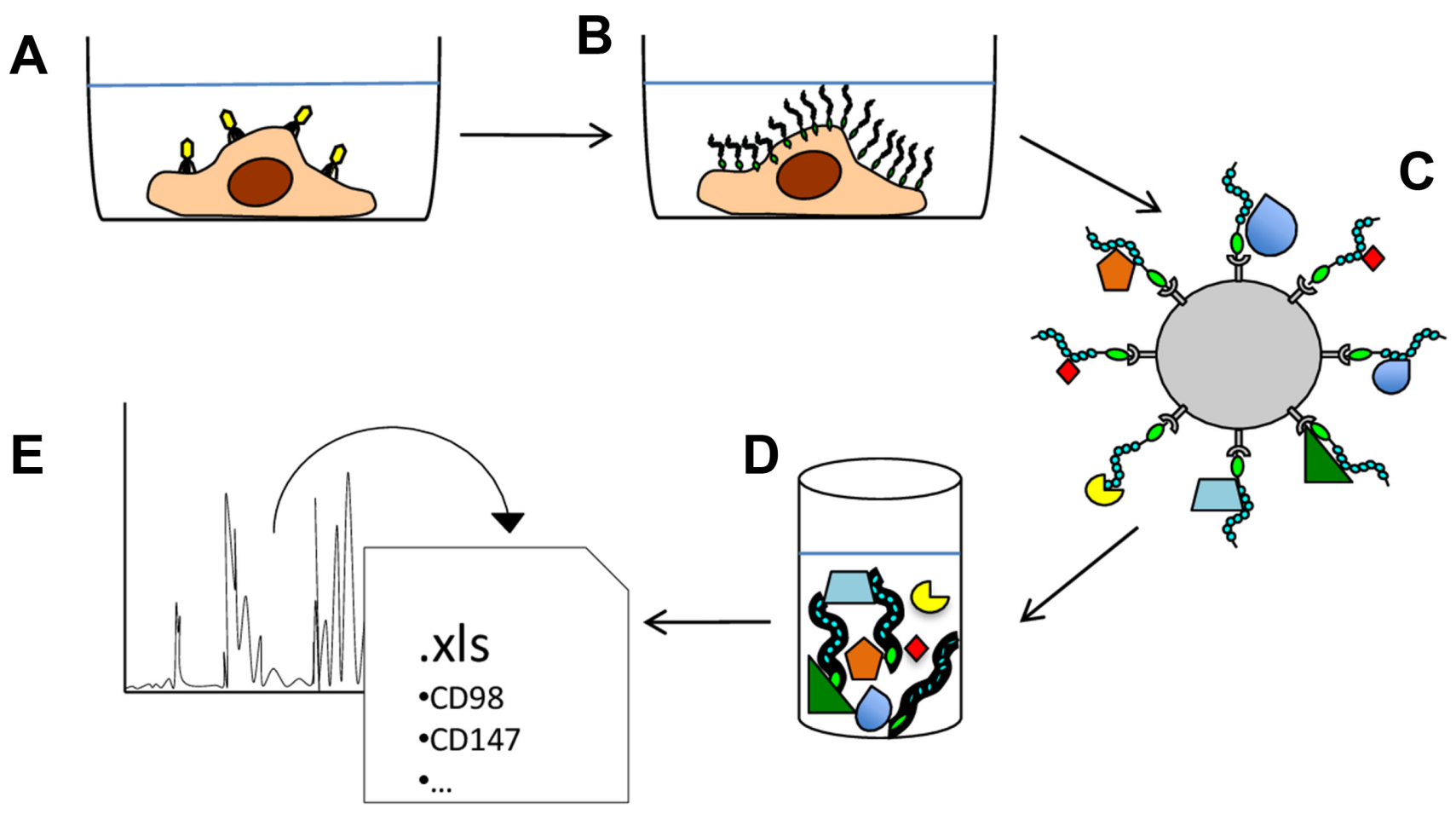

Figure 1: Schematic representation of the experimental approach used to identify PTPRJ-interacting proteins. (A) A549 lung cancer cells were transduced with a recombinant adenovirus carrying a cDNA coding for PTPRJ fused to a His6-tag. (B) transduced A549 cells were lysed and enriched membrane proteins were extracted. (C) PTPRJ-His6 and its candidate interactingproteins were isolated through poly(His)-avid magnetic beads; (D) beads-bound proteins were eluted and (E) analyzed for peptides identification by mass spectrometry. 
Table 1: List of significantly enriched proteins in PTPRJ-His6 pull-down with respect of the control experiment

\begin{tabular}{|c|c|c|c|c|c|c|c|}
\hline $\begin{array}{l}\text { Uniprot } \\
\text { Accession }\end{array}$ & Protein & Gene & $\begin{array}{l}\text { Sequence } \\
\text { Coverage }\end{array}$ & $\begin{array}{l}\text { Unique } \\
\text { Peptides }\end{array}$ & Peptides & $\begin{array}{l}\text { MEAN } \\
\text { M:L }\end{array}$ & $p$-value \\
\hline P20020 & Plasma membrane calcium-transporting ATPase 1 & ATP2B1 & 4.85 & 4 & 4 & 8.13 & 0.00 \\
\hline $\mathrm{H} 7 \mathrm{C} 5 \mathrm{Q} 2$ & $\begin{array}{l}\text { Acyl-coenzyme A thioesterase } 9, \text { mitochondrial } \\
\text { (Fragment) }\end{array}$ & АСОТ9 & 13.26 & 2 & 2 & 8.13 & 0.00 \\
\hline Q12913 & Receptor-type tyrosine-protein phosphatase eta & PTPRJ & 31.79 & 39 & 39 & 7.89 & 0.00 \\
\hline A0A0A0MR02 & $\begin{array}{l}\text { Voltage-dependent anion-selective channel protein } 2 \\
\text { (Fragment) }\end{array}$ & VDAC2 & 12.77 & 3 & 3 & 7.74 & 0.00 \\
\hline O95297 & Myelin protein zero-like protein 1 & MPZL1 & 14.13 & 3 & 3 & 7.43 & 0.00 \\
\hline P67936 & Tropomyosin alpha- 4 chain & TPM4 & 25.81 & 5 & 8 & 6.90 & 0.00 \\
\hline Q9H330 & Transmembrane protein 245 & TMEM245 & 2.31 & 2 & 2 & 6.54 & 0.00 \\
\hline P61019 & Ras-related protein Rab-2A & RAB2A & 19.34 & 3 & 3 & 6.53 & 0.00 \\
\hline Q9UH99 & SUN domain-containing protein 2 & SUN2 & 3.77 & 2 & 2 & 5.86 & 0.01 \\
\hline J3KNL5 & GRAM domain-containing protein 1B & GRAMD1B & 4.07 & 2 & 2 & 5.71 & 0.00 \\
\hline O75306 & $\begin{array}{l}\text { NADH dehydrogenase [ubiquinone] iron-sulfur protein } 2 \text {, } \\
\text { mitochondrial }\end{array}$ & NDUFS2 & 7.56 & 3 & 3 & 5.62 & 0.00 \\
\hline P42166 & Lamina-associated polypeptide 2 , isoform alpha & TMPO & 2.88 & 2 & 2 & 5.40 & 0.01 \\
\hline Q8NBU5 & ATPase family AAA domain-containing protein 1 & ATAD1 & 18.56 & 5 & 5 & 5.35 & 0.00 \\
\hline J3KTA4 & Probable ATP-dependent RNA helicase DDX5 & DDX5 & 9.28 & 5 & 6 & 5.17 & 0.00 \\
\hline F5H004 & Ras-related protein Rap-1b (Fragment) & RAP1B & 22.83 & 4 & 4 & 5.08 & 0.00 \\
\hline D6RBN9 & RELT-like protein 1 (Fragment) & RELL1 & 25.51 & 3 & 3 & 4.79 & 0.00 \\
\hline Q96ER9 & Coiled-coil domain-containing protein 51 & CCDC51 & 14.11 & 5 & 5 & 4.64 & 0.00 \\
\hline Q8N766 & ER membrane protein complex subunit 1 & EMC1 & 5.34 & 4 & 4 & 4.21 & 0.01 \\
\hline E9PB51 & RNA-binding protein 4 (Fragment) & RBM4 & 15 & 4 & 4 & 3.88 & 0.00 \\
\hline P51148 & Ras-related protein $\mathrm{Rab}-5 \mathrm{C}$ & RAB5C & 21.3 & 4 & 4 & 3.73 & 0.01 \\
\hline X6RFL8 & Ras-related protein Rab-14 (Fragment) & RAB14 & 24.86 & 5 & 5 & 3.62 & 0.00 \\
\hline P35580 & Myosin-10 & MYH10 & 10.17 & 7 & 17 & 3.59 & 0.00 \\
\hline P04083 & Annexin A1 & ANXA1 & 14.16 & 4 & 4 & 3.54 & 0.01 \\
\hline Q92896 & Golgi apparatus protein 1 & GLG1 & 19.42 & 22 & 22 & 3.47 & 0.00 \\
\hline P18031 & Tyrosine-protein phosphatase non-receptor type 1 & PTPN1 & 15.17 & 6 & 6 & 3.36 & 0.01 \\
\hline P14618 & Pyruvate kinase PKM & PKM & 47.46 & 21 & 21 & 3.20 & 0.00 \\
\hline O94826 & Mitochondrial import receptor subunit TOM70 & TOMM70A & 9.05 & 5 & 5 & 3.15 & 0.00 \\
\hline P49257 & Protein ERGIC-53 & LMAN1 & 20.2 & 10 & 11 & 3.13 & 0.00 \\
\hline P21980 & Protein-glutamine gamma-glutamyltransferase 2 & TGM2 & 8.3 & 6 & 6 & 2.95 & 0.00 \\
\hline P61011 & Signal recognition particle $54 \mathrm{kDa}$ protein & SRP54 & 17.86 & 7 & 7 & 2.94 & 0.00 \\
\hline P46940 & Ras GTPase-activating-like protein IQGAP1 & IQGAP1 & 14.3 & 17 & 17 & 2.94 & 0.00 \\
\hline P27105 & Erythrocyte band 7 integral membrane protein & STOM & 52.43 & 15 & 15 & 2.93 & 0.00 \\
\hline P35579 & Myosin-9 & MYH9 & 37.24 & 62 & 73 & 2.89 & 0.00 \\
\hline P14625 & Endoplasmin & HSP90B1 & 16.06 & 11 & 11 & 2.84 & 0.01 \\
\hline F5GZS6 & $4 \mathrm{~F} 2$ cell-surface antigen heavy chain $(\mathrm{CD} 82 \mathrm{hc})$ & SLC3A2 & 23.04 & 13 & 13 & 2.80 & 0.00 \\
\hline A0A0A0MS51 & Gelsolin & GSN & 10.56 & 7 & 7 & 2.80 & 0.01 \\
\hline P08107 & Heat shock $70 \mathrm{kDa}$ protein $1 \mathrm{~A} / 1 \mathrm{~B}$ & HSPA1A & 15.76 & 10 & 11 & 2.71 & 0.00 \\
\hline P05026 & Sodium/potassium-transporting ATPase subunit beta-1 & ATP1B1 & 17.82 & 4 & 4 & 2.71 & 0.01 \\
\hline P36542 & ATP synthase subunit gamma, mitochondrial & ATP5C1 & 25.17 & 8 & 8 & 2.65 & 0.00 \\
\hline O94979 & Protein transport protein Sec31A & SEC31A & 7.05 & 8 & 8 & 2.64 & 0.00 \\
\hline P27824 & Calnexin & CANX & 15.2 & 8 & 8 & 2.47 & 0.01 \\
\hline Q13813 & Spectrin alpha chain, non-erythrocytic 1 & SPTAN1 & 4.94 & 9 & 9 & 2.47 & 0.00 \\
\hline P08670 & Vimentin & VIM & 21.03 & 7 & 10 & 2.45 & 0.01 \\
\hline P25705 & ATP synthase subunit alpha, mitochondrial & ATP5A1 & 21.7 & 11 & 11 & 2.40 & 0.00 \\
\hline P19105 & Myosin regulatory light chain $12 \mathrm{~A}$ & MYL12A & 34.5 & 5 & 5 & 2.39 & 0.00 \\
\hline P31327 & Carbamoyl-phosphate synthase [ammonia], mitochondrial & CPS1 & 17.47 & 23 & 25 & 2.28 & 0.00 \\
\hline $\mathrm{H} 7 \mathrm{C} 463$ & MICOS complex subunit MIC60 (Fragment) & IMMT & 15.66 & 10 & 10 & 2.16 & 0.01 \\
\hline
\end{tabular}

Section of potential PTPRJ-interacting protein list obtained by mass spectrometry analysis. Uniprot Accession numbers along with a brief description of protein functions were included in the table. "Sequence coverage" value corresponds to the total quantity of each protein present in the samples; "Unique Peptides" indicates the number of exclusive peptides found for each protein group while "Peptides" correlates with the total number of peptides assigned to each protein group. Medium/light ratio (Mean M:L) represents the fold change between eluted sample and eluted control. For more details see Supplementary Information 1. 
with Ad PTPRJ at MOI50 were treated with MG132, a proteasome inhibitor; cell extracts were purified twentyfour, forty-eight, and seventy-two hours after infection. As expected, Ad PTPRJ-transduced A549 cells treated with MG132, did not undergo CD98hc protein levels decrease compared to MG132-untreated cells transduced with Ad PTPRJ, where we observed a time-dependent reduction of CD98hc protein levels. These data strongly indicate that PTPRJ induces CD98hc proteasomal-mediated

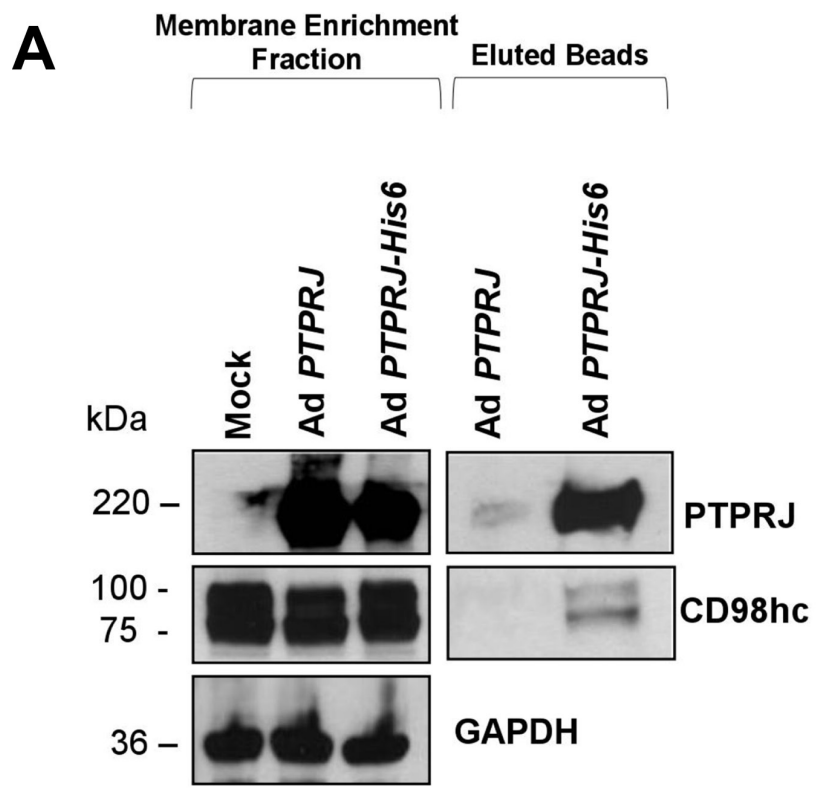

degradation (Figure 4C). In order to validate the PTPRJdependent effect on the ubiquitin-mediated CD98hc degradation, we also performed a protein stability assay in the presence of cycloheximide. As expected on the basis of the ubiquitination assay (Figure 4B), the degradation of CD98hc appeared steadily and significantly increased in the presence of virus-dependent PTPRJ overexpression, compared to its orthologic control (Figure 4D).
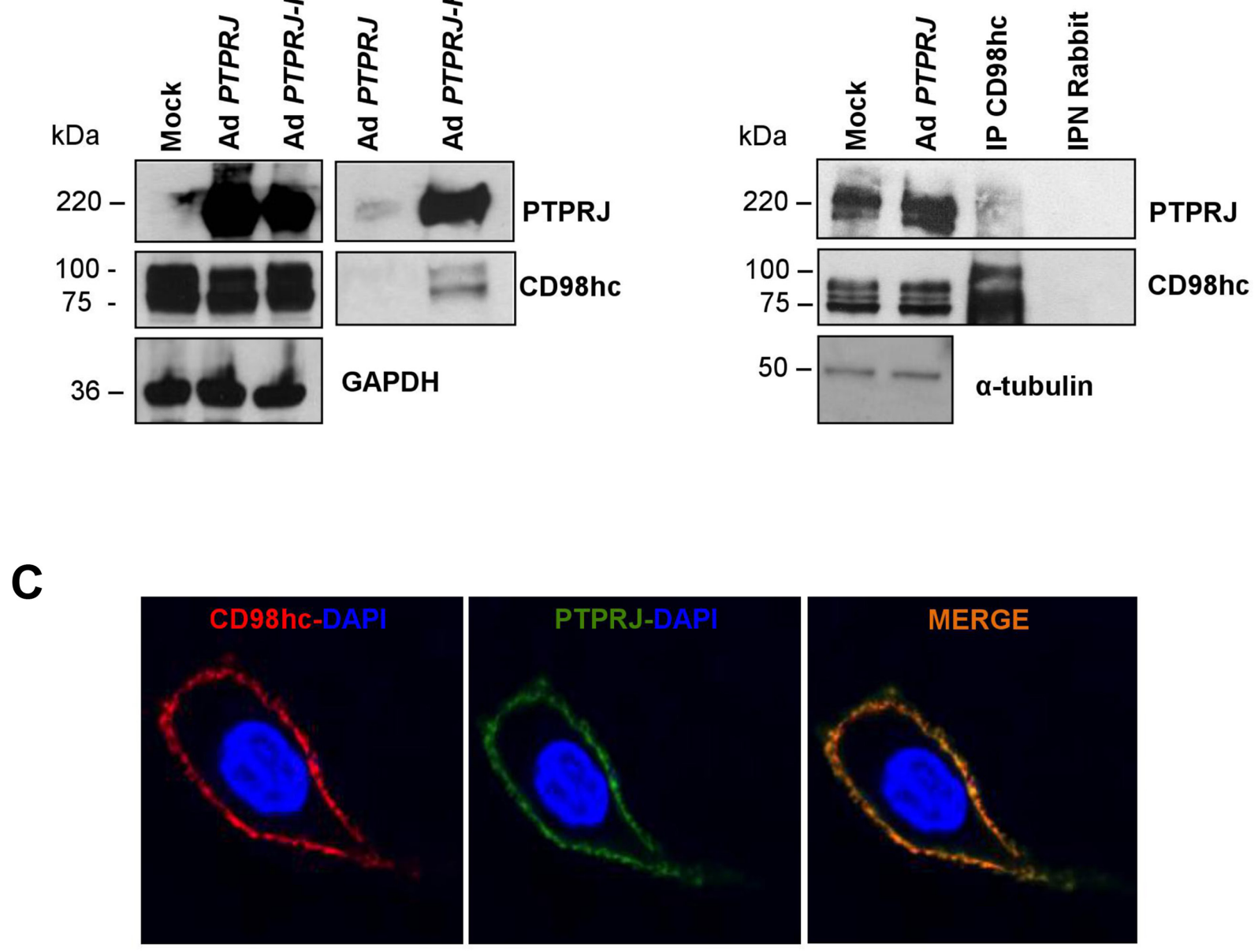

Figure 2: PTPRJ interacts and colocalizes with CD98hc. (A) A549 lung cancer cells were transduced either with Ad PTPRJ (used as a control) or Ad PTPRJ-His6. Seventy-two hours after infection, cells were lysed and cell membranes enriched. Mature integral fusion protein PTPRJ-His6 were purified through poly(his)-avid magnetic beads, loaded on a polyacrylamide gel, transferred to nitrocellulose filter, and probed with CD98hc antibody. (B) A549 lung cancer cells were transduced with a recombinant Ad PTPRJ. Twenty-four hours after infection, cells were lysed and proteins extracted. Total protein lysates were immunoprecipitated with IgG and CD98hc. Proteins were loaded on a polyacrylamide gel, transferred to nitrocellulose filter, and probed with PTPRJ antibody. IgG was used to demonstrate that without CD98hc, PTPRJ is absent in the purified protein extract. (C) A549 cells were transduced with Ad PTPRJ at MOI30. Twenty-four hours later, A549 cells were incubated with PTPRJ mAb and CD98hc mAb; afterwards, secondaries rabbit-633 Ab (red) and mouse-PE $\mathrm{Ab}$ (green) were added to stain cells, as described in Methods, and observed by confocal microscopy. Merge of the images indicated the colocalization of PTPRJ and CD98hc. 


\section{Simultaneous PTPRJ overexpression and CD98he knockdown inhibits cell growth and migration of A549 cancer cells and effectively triggers their apoptosis}

To investigate the effects of PTPRJ and CD98he interaction on cell proliferation, we either transduced A549 cells with Ad PTPRJ or silenced CD98hc through specific siRNA (Figure 5A). While CD98hc knockdown only slightly impaired cell proliferation compared to mocktransfected cells, PTPRJ overexpression significantly reduced A549 cell number; however, the combination of both PTPRJ overexpression and CD98hc knockdown resulted in a further decrease of cell proliferation compared to PTPRJ overexpression alone (Figure 5B). We also examined, by clonogenic assay, the anticancer properties of PTPRJ overexpression in combination with siCD98hc; this treatment significantly decreased A549 ability to form colonies compared to controls (Figure 5C). In addition, by using the same experimental design reported above, we also performed two wound-healing assays by observing either A549 cells cultured under conventional

\section{A}

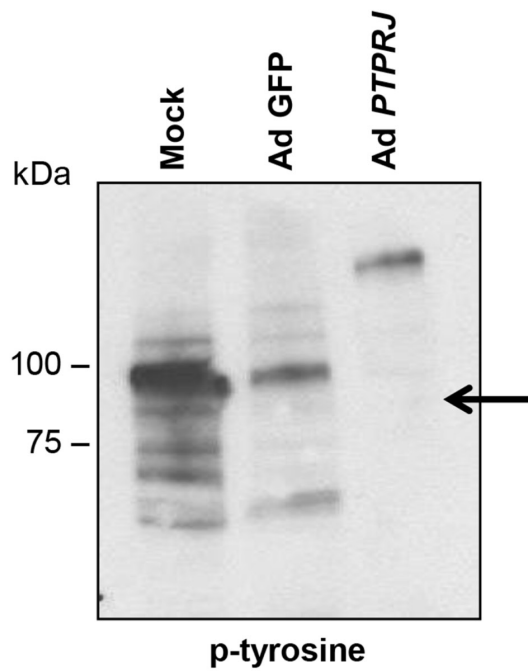

C
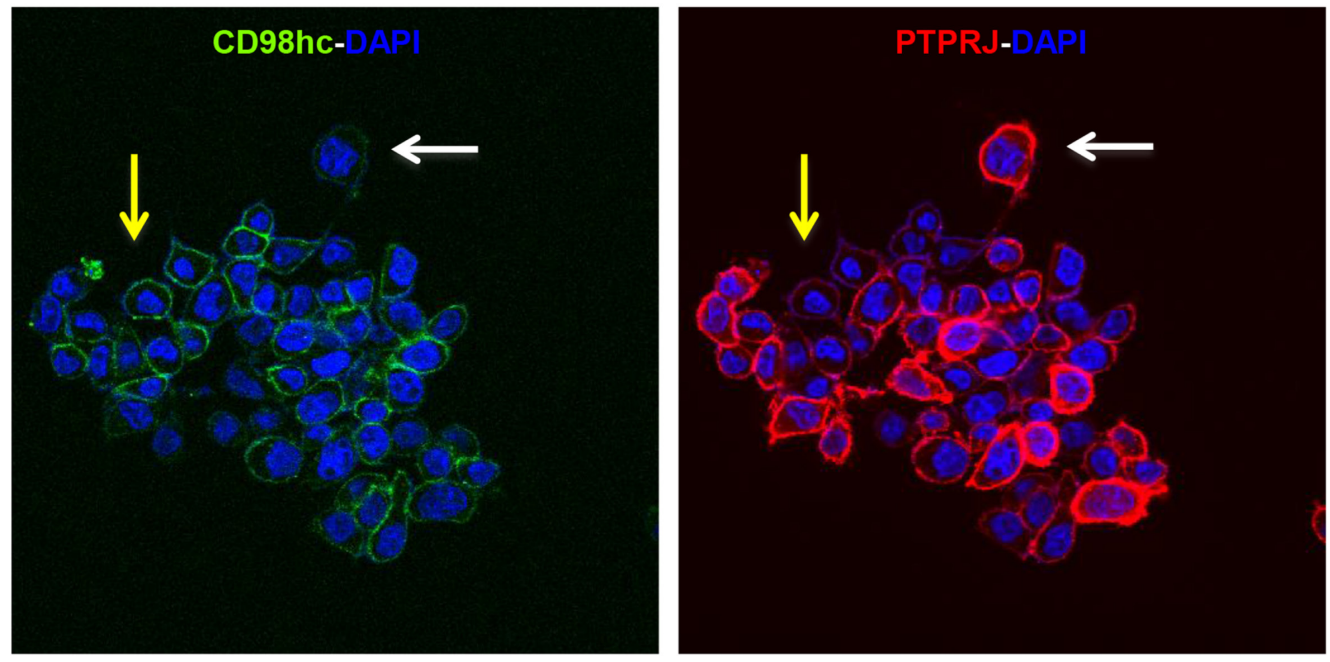

Figure 3: PTPRJ overexpression dephosphorylates CD98hc and downregulates its protein levels. (A, B) A549 cells were seeded in $100 \mathrm{~mm}$ culture dishes and, after twenty-four hours, transduced by a recombinant Ad PTPRJ at MOI50. Forty-eight hours later, cells were lysed and extracted proteins loaded on polyacrylamide gel, transferred to nitrocellulose filter, and analyzed by Western blot through CD98hc, PTPRJ and p-tyrosine antibodies. $\gamma$-tubulin was used to normalize protein loading. (C) An immunofluorescence was also performed. A549 cells were transduced with Ad PTPRJ at MOI50. Forty-eight hours later, A549 cells were incubated with PTPRJ mAb and $\mathrm{CD} 98 \mathrm{hc} \mathrm{mAb}$; afterwards, secondary rabbit-633 Ab (green) and mouse-PE Ab (red) were added to stain cells, as described in Materials and Methods, and observed by confocal microscopy. CD98hc levels decrease with PTPRJ overexpression (white arrow) in contrast with a lower expression of PTPRJ where CD98hc levels do not change (yellow arrow). 
conditions (Figure 5D and 5E) or, on the other hand, in serum-free culture media (Figure 5F). Consistently, PTPRJ overexpression plus CD98hc knockdown resulted in a decrease of cell motility compared to controls in both experiments (Figure 5D, 5E, and 5F).

To assess whether A549 cells undergo programmed cell death after PTPRJ adenovirus-mediated overexpression and CD98hc knockdown we performed an annexin/PI assay by flow cytometry. Forty-eight
(Figure 5G), and seventy-two hours after treatment (Figure 5G and 5H), we observed that CD98hc siRNA plus PTPRJ overexpression triggered apoptosis in a much more effective way than controls. In fact, while CD98hc silencing and Ad PTPRJ overexpression alone showed a low percentage of apoptotic cells $(\sim 10 \%$ and $\sim 5 \%$, respectively), the combination of both resulted in a dramatic increase in the number of apoptotic cells (more than $50 \%$ of dead cells; see Figure $5 \mathrm{G}$ and $5 \mathrm{H}$ ).
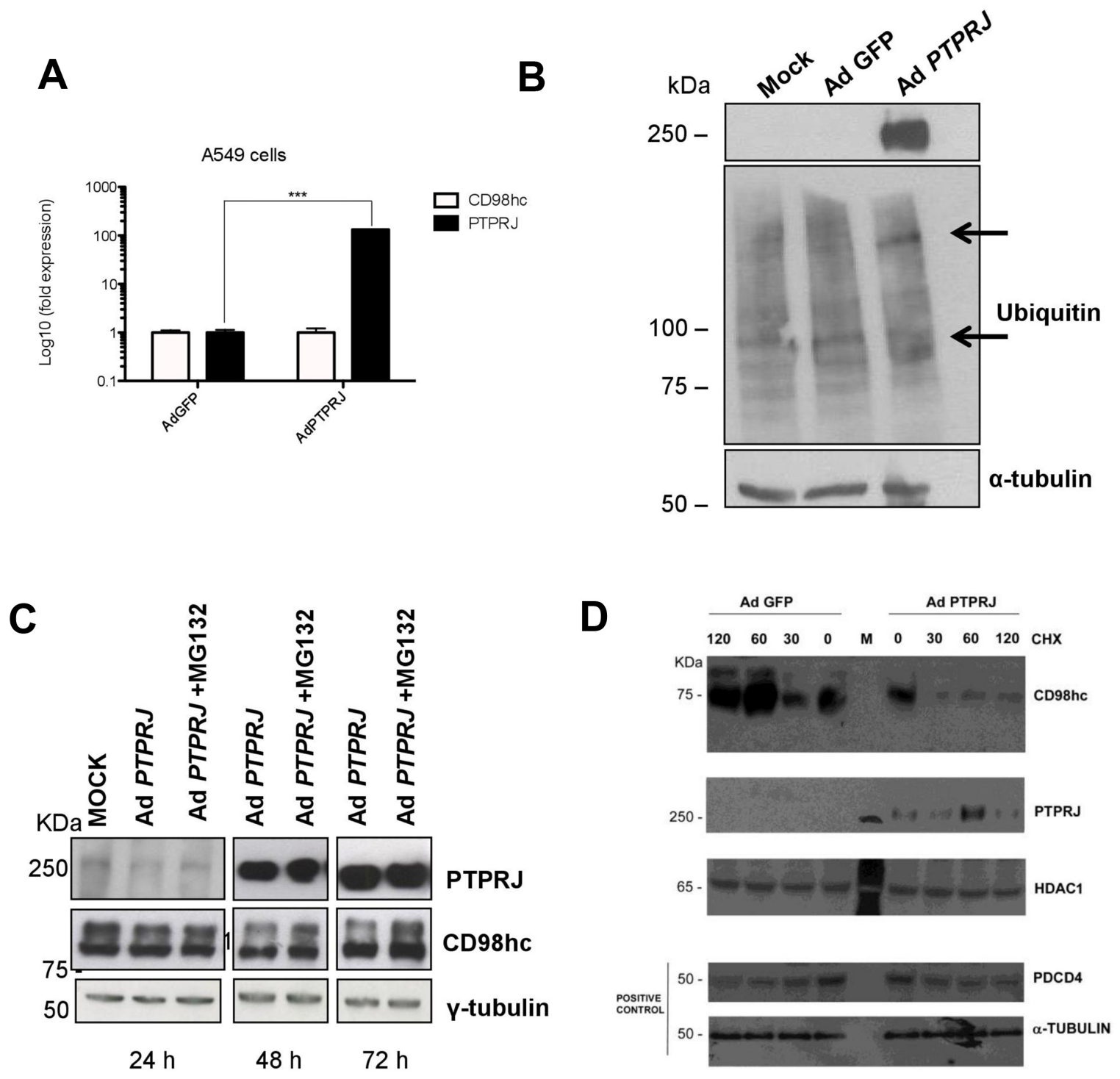

Figure 4: PTPRJ mediates CD98hc stability and proteasome degradation. (A) A549 cells were seeded in $100 \mathrm{~mm}$ culture dishes and, twenty-four hours later, transduced by a recombinant Ad PTPRJ at MOI50. After seventy-two hours, cells were lysed and retro-transcribed mRNA was analyzed by qRT-PCR using specific primers amplifying both CD98hc and PTPRJ. Values were normalized to HPRT RNA levels. ${ }^{*} P<0.05$. (B) A549 cells were transduced with Ad PTPRJ at MOI50; cells were lysed and extracted proteins loaded on polyacrylamide gel, transferred to nitrocellulose filter, and analyzed by Western blot through PTPRJ and ubiquitin antibodies. $\alpha$-tubulin was used to normalize protein loading. (C) PTPRJ-overexpressing A549 cells were lysed after a $6 \mathrm{~h}$ treatment with 10 microM MG132, a proteasome inhibitor. The protein extract was analyzed by Western blot analysis evaluating CD98hc levels. $\gamma$-tubulin antibody was used to normalize. (D) A549 cells were seeded in $100 \mathrm{~mm}$ culture dishes. The cells were transduced by a recombinant Ad PTPRJ or Ad GFP as a control both at MOI50. Fourty-eight hours after infection, cells were treated with cycloeximide $100 \mu \mathrm{g} / \mathrm{mL}$ at different time points. Total proteins were extracted, loaded on polyacrylamide gel and stained with anti CD98hc, PTPRJ and Pdcd4. Equal loading was verified by tubulin and HDAC. 


\section{Poor overall survival of non-small cell lung cancer (NSCLC) patients displays low PTPRJ and high $S L C 3 A 2$ gene expression}

To understand if our findings might have a clinical significance, we interrogated the clinical public database canEvolve (www.canevolve.org): non-small cell lung cancer patients who experienced the longest survival rate showed lower SLC3A2 and higher PTPRJ gene expression compared to patients with dismal prognosis that, in turn, exhibited the highest and the lowest SLC $3 A 2$ and PTPRJ gene expression, respectively (Figure 6A and 6B).

\section{DISCUSSION}

As widely reported, the targeting of diseaseassociated molecules has become very important for the development of new drugs that can interfere with their
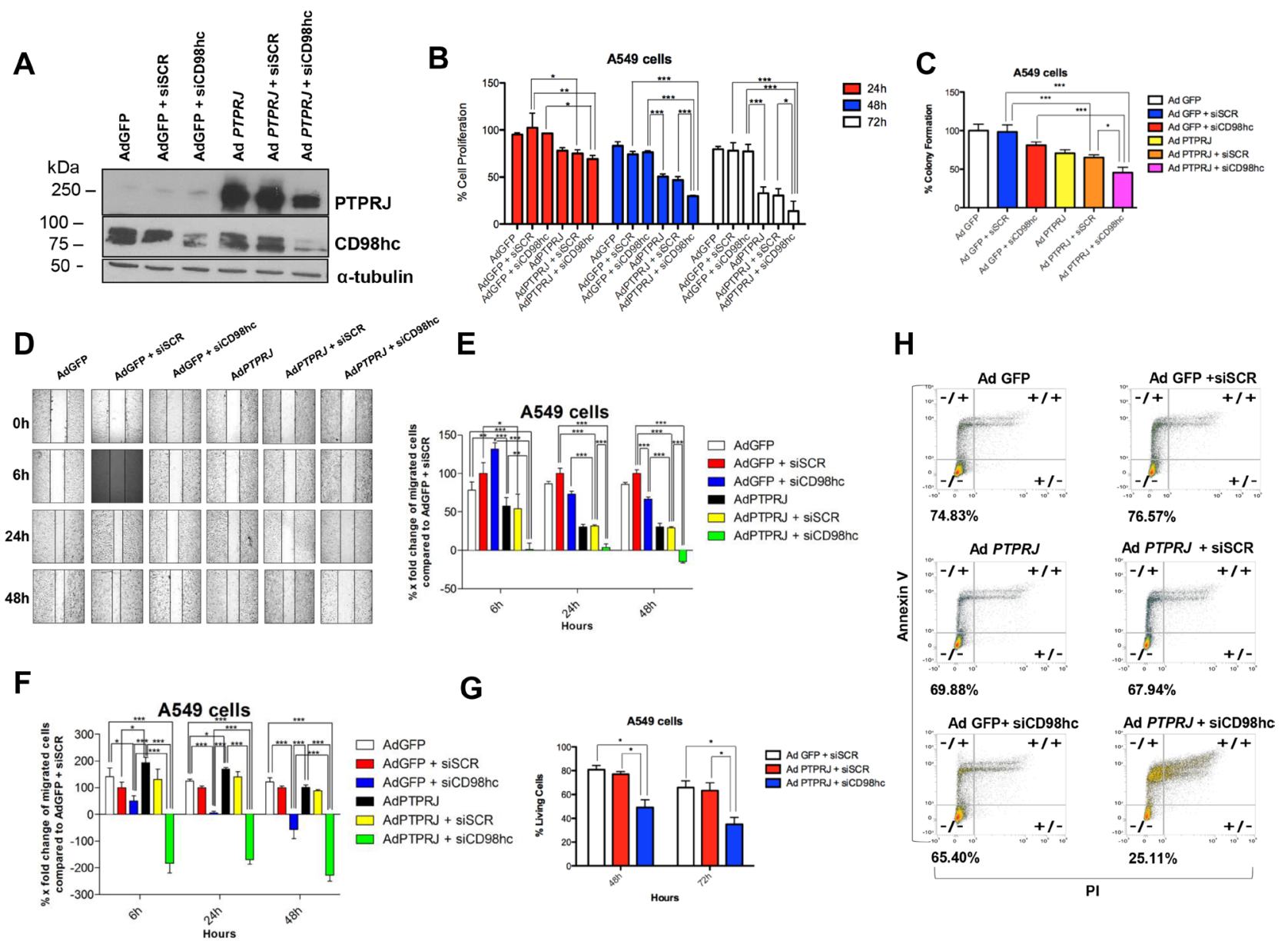

Figure 5: PTPRJ overexpression synergizes with CD98hc silencing in decreasing proliferation and migration of cells A549 and effectively triggers their programmed cell death. (A) CD98hc silencing was combined to PTPRJ overexpression. A549 cells were transfected with siCD98hc $(400 \mathrm{nM})$ and after $6 \mathrm{~h}$ transduced with Ad PTPRJ (MOI50). After $72 \mathrm{~h}$ cells were lysed and extracted proteins loaded on polyacrylamide gel, a Western blot analysis was performed using cd98hc and PTPRJ antibodies. $\alpha$-tubulin was used to normalize protein loading. (B) Proliferation of A549 cells transfected with siCD98hc (400 nM) and, six hours later, transduced with Ad PTPRJ at MOI50. Cell viability was measured twenty-four, forty-eight, and seventy-two hours after infection by CellTiter-Glo ${ }^{\circledR}$ Luminescent assay; values were normalized to Ad GFP. ${ }^{*} P<0.05$ value, analyzed by ANOVA, was compared to control. (C) PTPRJ overexpression along with CD98he downregulation significantly decreases A549 cell colony growth. The graph shows the percentage of the number of colonies formed on the culture plate twelve days after treatment. ${ }^{*} P<0.05$. (D, E) Migration of A549 cells transfected with siCD98hc $(400 \mathrm{nM})$ and, after six hours following transfection, transduced either with Ad PTPRJ or Ad GFP at MOI50. Wound-healing assay was performed by measuring the distances between the points of the scratch after six, twenty-four and forty-eight hours following the wound formation. X-fold changes of each sample, compared to its corresponding at $t=0 \mathrm{~h}$, were calculated. ${ }^{*} P<0.05$ compared with negative control (Ad GFP + siSCR), analysed by ANOVA. (F) The same experimental design was also applied to perform a cell migration assay in serum-free conditions. (G, H) PTPRJ overexpression with CD98hc silencing increases A549 cell apoptosis. A549 cells were transfected with siCD98hc $(400 \mathrm{nM})$ or siSCR $(400 \mathrm{nM})$ and, after six hours following transfection, transduced with either Ad PTPRJ or with Ad GFP at MOI20. Annexin assay was performed forty-eight (panel g) and seventy-two hours (panels g and h) after the treatment; the percent of living cells is reported in both panels. ${ }^{*} P<0.05$ compared to negative control (Ad GFP + siSCR), was analysed by ANOVA. 
aberrant activity; this approach has already provided new therapies for disease treatment [34]. Protein tyrosine phosphatases are very interesting targets for the development of novel drugs, as aberrant tyrosine phosphorylation is involved in human diseases including cancer [35-37]. It was extensively demonstrated that PTPRJ negatively modulates mitogenic signaling by dephosphorylating a number of downstream proteins including receptor tyrosine kinases [18-21]. These findings reinforce the idea of PTPRJ as a target for triggering antiproliferative signals. Indeed, although the use of two biological PTPRJ ligands recently discovered (syndecan-2 and TSP-1) [16, 17] appears of difficult translation into clinics, both CD148 monoclonal antibodies [13] and synthetic PTPRJ agonist peptides seem promising tools for the development of new anticancer drugs $[14,15]$.

However, as it is apparent from a large body of literature that PTPs are not only involved in cell proliferation [36, 38-40], it is our opinion that we are still very far from understanding all biological processes regulated by PTPRJ. This consideration forced us to seek for novel candidate PTPRJ-interacting proteins. Insights from this approach could expand, not only our knowledge about PTPRJ signaling, but also supply opportunities for the development of novel drugs of easier application compared to CD148 monoclonal antibodies and PTPRJ peptides.

Here, we validated CD98hc as an interesting PTPRJ partner. It is well known that CD98hc has two biochemical functions: a) it binds to cytoplasmatic tails of integrin- $\beta$ chains mediating adhesive signals that control cell spreading and proliferation and b) it forms a heterodimeric complex with specific light chains of amino acid transporters such as LAT1 and LAT2 with nutrient function [41]. Recent studies have demonstrated LAT1 overexpression in lung cancer, esophageal carcinoma and ovarian tumors [42]; moreover the overexpression of LAT1 is a key factor for the prediction of poor prognosis in non-small cell lung cancer and tends to increase from low-grade to high-grade neuroendocrine tumors of the lung [42, 43]. Since LAT1 light chain requires a covalent association with CD98hc for its functional expression in plasma membrane [44], the heavy chain could play a key role in tumor development and progression. In fact, it is reported that high CD98hc immunoreactivity correlates with high LAT1 expression [45]; moreover, overexpression of LAT1 light chain and CD98hc plays an important role in the progression and metastasis of several human neoplasms since the level of both chains increase markedly in the metastatic sites compared with the primary sites of the tumor [46]. On the contrary, CD98hc is not involved in the intrinsic transport properties of LAT1, as recently demonstrated [47]. In the present study we demonstrate that PTPRJ both dephosphorylates and promotes CD98hc ubiquitylation and proteasome degradation and accordingly, that CD98hc protein downregulation is dependent on PTPRJ overexpression in lung cancer cells. It is well established that initial signals could result in diverging effects; in this specific case, this applies to PTPRJ in terms of protein stabilization or degradation. In fact, while the cell cycle
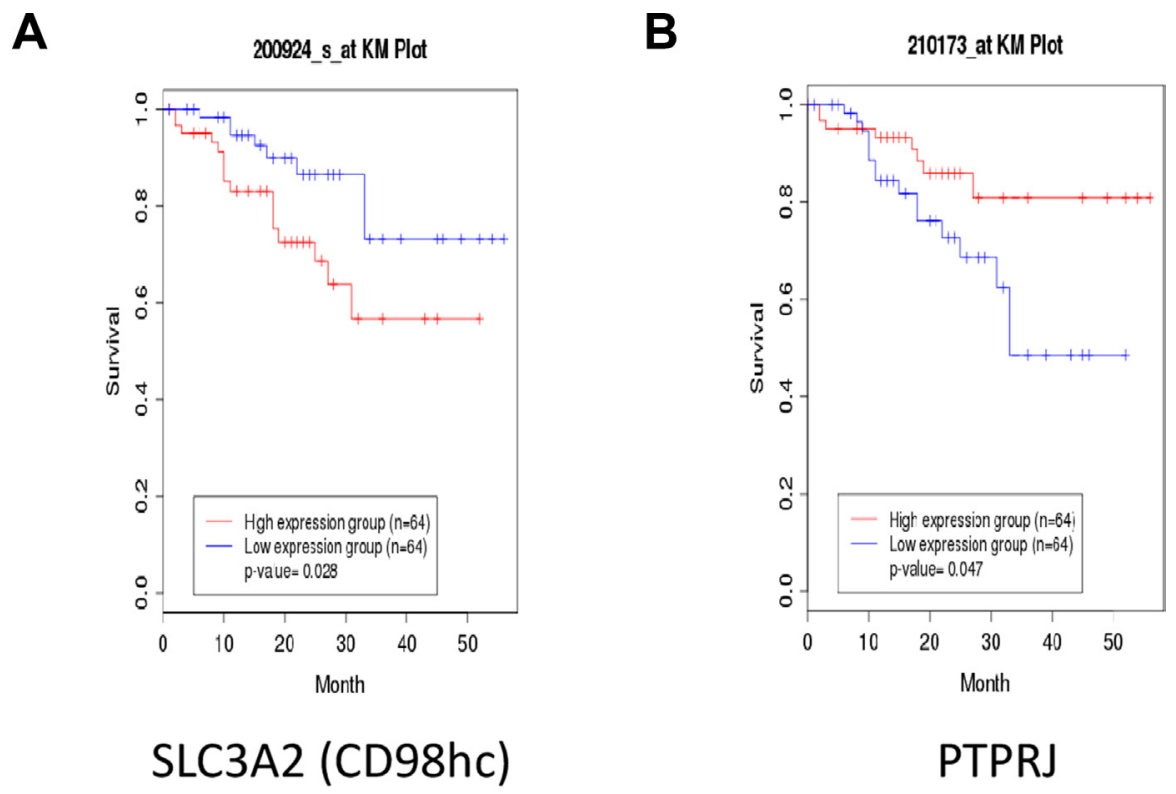

Figure 6: Non-small Cell Lung Cancer (NSCLC) patients with poor outcome show enhanced $S L C 3 A 2$ and decreased PTPRJ expression levels. Public database canEvolve (www.canevolve.org) was interrogated to assess both SLC 3A2 and PTPRJ gene expression; SLC3A2 was found to be increased in NSCLC patients with poorer outcomes (panel A) while, in the same patients, PTPRJ gene expression decreased (panel B). 
inhibitor $\mathrm{p} 27^{\mathrm{kip} 1}$ protein is protected from degradation by PTPRJ-mediated proteasome inhibition, here we demonstrated that the CD98hc oncoprotein is addressed by PTPRJ activity to proteasome-mediated degradation, with a clear-cut effect on its stability. As the discovery of small molecules able to selectively control the degradation of proteins involved in cancer represent an intriguing path for the generation of novel and potentially more effective anticancer drugs [48, 49], these findings strongly and further encourage the development of drugs activating PTPRJ and/or inhibiting CD98hc [50]; this idea is also supported by our results demonstrating that PTPRJ overexpression, combined to CD98hc-silencing, impaired both cell proliferation and migration as well as effectively triggered apoptosis of lung cancer cells to a much higher extent compared to controls. Interestingly, an anticancer therapy targeted to CD98-specific through a human monoclonal antibody, IGN523, elicited a strong antibody-dependent cell-mediated cytotoxicity (ADCC) activity resulting in cell death. Interestingly, IGN523 is currently being evaluated in a Phase I clinical trial for acute myeloid leukemia [51].

The relationship between PTPRJ and CD98hc is interesting also from a clinical point of view since nonsmall cell lung cancer (NSCLC) patients who experienced the longest survival presented lower expression of CD98hc and higher expression of PTPRJ genes compared to patients with poor outcome (www.canevolve.org). These data suggest that both PTPRJ and SLC $3 A 2$ transcripts could potentially be considered as interesting biomarkers of lung cancer progression.

However, we consider the PTPRJ-CD98hc interaction as the very beginning of a number of mechanistic studies based on the protein network involving PTPRJ itself. As an example, it has been reported that CD98hc interacts with CD147, a member of the superfamily of immunoglobulin, that coordinates the transport of both amino acids and lactate in cancer cells $[52,53]$. Interestingly, in our raw list of proteins potentially interacting with PTPRJ we also found CD147, even though the enrichment in PTPRJ-His6 observed by mass spectrometry was below the significance threshold (Supplementary Table 1); this information, validated by preliminary experiments of co-immunoprecipitation indicating that PTPRJ interacts with CD147, stimulates further investigations in order to shed lights about the role of the PTPRJ/CD98hc/CD147 complex also in the energetic metabolism of cancer cells.

In conclusion, the development of drugs aimed to both trigger PTPRJ activity and inhibit CD98hc signaling in combination, could represent an intriguing opportunity for the treatment of cancer patients with poor prognosis, based on the simultaneous targeting of several hallmarks important in the biology of a cancer cell [54], including proliferation, apoptosis, angiogenesis, and energetic metabolism.

\section{MATERIALS AND METHODS}

\section{Cell culture, transfection and infection experiments}

A549 lung cancer cells were cultured in RPMI medium 1640 supplemented with 10\% FBS (SigmaAldrich) and were maintained at $37^{\circ} \mathrm{C}$ in a humidified atmosphere of $5 \% \mathrm{CO}_{2}$. Transfections were made with Lipofectamine 2000 (Invitrogen) by following the manufacturer's instructions; $3.5 \times 10^{5}$ A549 cells were seeded in 6-well plates and transfected with 100 pmol of either CD98hc-specific or scrambled siRNAs (Life Technologies). Infections were carried out by infecting $3.5 \times 10^{5}$ A549 cells with Ad PTPRJ at multiplicity of infection (MOI) 50. The generation of recombinant Ad PTPRJ and Ad PTPRJ-His6 was performed as previously described [14].

\section{Identification of PTPRJ-binding proteins by mass spectrometric analysis}

PTPRJ-His6 recombinant protein was overexpressed in A549 by infecting $5 \times 10^{7}$ cells with Ad PTPRJ-His6 at MOI30. Three days after infection, cell lysis was performed with Mem-PER Eukaryotic Membrane Protein Extraction Kit (Pierce) to enrich mature transmembrane proteins. Mature recombinant PTPRJ-His6 protein and its candidate interactors were purified through MagneHis Protein Purification System (Promega) following the manufacturer's protocol. Beads were extensively washed with HEPES $100 \mathrm{mM}$ with added $\mathrm{NaCl} 500 \mathrm{mM}(\mathrm{pH}$ $7.5)$ to remove unbound proteins. Proteins were finally eluted from the beads by using $100 \mathrm{mM}$ HEPES and $500 \mathrm{mM}$ imidazole elution buffer $(\mathrm{pH}$ 7.5). The eluates $(50 \mu \mathrm{L})$ from PTPRJ-His6 and control (wild-type PTPRJ) were mixed with $100 \mu \mathrm{L}$ of Tris buffer $(150 \mathrm{mM}, \mathrm{pH} 8)$; proteins were reduced by DTT $(100 \mathrm{mM}, 15 \mu \mathrm{L})$ and alkylated by iodoacetamide $(200 \mathrm{mM}, 18 \mu \mathrm{L})$. After quenching excess iodoacetamide by the addition of $3 \mu \mathrm{L}$ of DTT solution, $400 \mathrm{ng}$ of Proteomics grade trypsin (Sigma) were added, and the enzymatic reaction was allowed to proceed overnight at $37^{\circ} \mathrm{C}$ with shaking.

The peptide mixtures were acidified with trifluoroacetic acid (TFA, final concentration $0.5 \%$ ) and purified by solid phase extraction (SPE cartridges HLB, 1 cc, Waters). Concentrated eluates were labeled by dimethyl labeling, mixed, purified and fractionated by strong cation exchange (SCX) StageTips as described in Varano et al. [55] PTPRJ-His6 sample was labeled "heavy", whereas the control was labeled "light". The SCX fractions $(n=6)$ were evaporated to dryness and reconstituted in $8 \mu \mathrm{L}$ of $2 \%$ acetonitrile $/ 0.1 \%$ formic acid. Mass spectrometry analysis was performed on a Q-Exactive Hybrid Quadrupole-Orbitrap Mass Spectrometer coupled online to an Easy nano-LC1000 system (Thermo Fisher 
Scientific, Germany) as described [55] using a TOP-12 data-dependent method. Raw data were processed by Proteome Discoverer 1.4 (Thermo Fisher Scientific, Germany) using the Sequest algorithm and searched against the Uniprot Human reference proteome database (March 2015, 67948 sequences). The search criteria were set as follows: enzyme trypsin, maximum two missed cleavages, Dimethyl (Any N-Terminus), Dimethyl (K), Carbamidomethyl (C) as static modifications (dimethyl modifications were set to either "light" (L) or "medium" (M) in two parallel searches), Oxidation (Met) as dynamic modification, MS tolerance $15 \mathrm{ppm}, \mathrm{MS} / \mathrm{MS}$ tolerance $0.02 \mathrm{Da}$. A FDR of $1 \%$ at the peptide level was estimated using the Target Decoy PSM Validator node available in Proteome Discoverer. A minimum of two peptide identifications per protein was required.

Protein quantification was performed in Proteome Discoverer 1.4 using the following parameters: minimum quantification value threshold $=0$, missing quantification values replaced with minimum intensity, maximum allowed fold change $=100$, ratios above maximum allowed fold change for quantification: not used, \% coisolation excluding peptides from quantification $=100$, quantification on all peptides. Normalization of M:L was performed on $\mathrm{PD}$, using the protein median $\mathrm{M}: \mathrm{L}$ value.

Permutation statistical analysis of the peptide ratios was performed using Quantitative Proteomics $p$-value Calculator (http://qppc.di.uq.edu.au/) [56]. Number of permutations was set to 10,000 . Proteins increased in the PTPRJ-His6 pull-down with $p$-values $<0.01$ were considered significantly enriched. Gene ontology (GO) and protein network analysis of the significantly altered proteins was performed using STRING v10.5 (https:// string-db.org/) [57]. The interaction score was set to 0.4 ; protein interactors were query proteins only.

\section{Co-immunoprecipitation and Western blot analysis}

Total proteins were extracted with Igepal CA630 lysis buffer containing 50 mMTris- $\mathrm{HCl} \mathrm{pH} 7.5$, $150 \mathrm{mMNaCl}, 0.5 \%$ Igepal CA-630, $1 \mathrm{mM} \mathrm{Na} \mathrm{VO}_{4}, 25$ mMNaF, 2 mM PMSF, 8 nMAprotinin; enriched plasma membrane proteins, used for both mass spectrometry and immunoprecipitations analyses, were obtained using Mem-PER Eukaryotic Membrane Protein Extraction Kit (Pierce). For CD98hc immunoprecipitation, cell extracts were incubated overnight at $4^{\circ} \mathrm{C}$ with $\mathrm{CD} 98 \mathrm{hc}$ antibody and then overnight with $20 \mu \mathrm{l}$ of protein $\mathrm{A} / \mathrm{G}$ Plus-Agarose (Santa Cruz Biotechnology). Pellets were washed five times with $1 \mathrm{ml}$ of lysis buffer, resuspended in Laemmli sample buffer $2 \times$ and subjected to SDS-polyacrylamide electrophoresis (SDS-PAGE) [58]. For PTPRJ immunoprecipitation, MagneHIS Protein Purification System (Promega) was used as described above. For Western blot analysis, proteins $(50 \mu \mathrm{g})$ were loaded and separated on polyacrylamide gels and transferred to nitrocellulose filter membranes. Membranes were blocked in 5\% non-fat dry milk, incubated with primary PTPRJ (R\&D Systems), CD98hc (Cell Signaling Technology), p-Tyr, Ubiquitin, $\gamma$-tubulin, $\alpha$-tubulin and GAPDH antibodies (Santa Cruz Biotechnology), detected by the appropriate secondary antibodies (Santa Cruz Biotechnology) and revealed by enhanced chemiluminescence (ECL; Amersham Inc.).

\section{Immunofluorescence}

A549 cells were fixed with 4\% paraformaldehyde at $4^{\circ} \mathrm{C}$ for $30 \mathrm{~min}$, rinsed with distilled $\mathrm{H}_{2} \mathrm{O}$ and then blocking in $1 \%$ BSA was performed for $1 \mathrm{~h}$ at room temperature. Cells were subsequently incubated for $2 \mathrm{~h}$ at room temperature with PTPRJ antibody (1:40), rinsed with distilled $\mathrm{H}_{2} \mathrm{O}$ and permeabilized with ice-cold $100 \% \mathrm{MeOH}$ for $15 \mathrm{~min}$ at $-20^{\circ} \mathrm{C}$. Afterwards, cells were washed and blocking was performed again. Cells were, then, incubated overnight at $4^{\circ} \mathrm{C}$ with $\mathrm{CD} 98 \mathrm{hc}$ antibody (1:800). After being washed with PBS two times, PE-labeled anti-mouse IgG $(1: 25)$ and Alexa Fluor 633-labeled anti-rabbit (1:500) (Thermo-Fisher Scientific) were added as secondary antibodies and DAPI (1:1000) for nuclei staining. Immunofluorescence was visualized with a laser-scanning confocal imaging system.

\section{Cycloeximide assay: protein stability}

Treatment with cycloeximide (CHX) $100 \mu \mathrm{g} / \mathrm{mL}$ was performed on $5 \times 10^{5}$ A549 cells, 48 hrs after infection with either Ad PTPRJ (MOI50) or Ad GFP, as a control. The treatment was added at different time point (0, 30 minutes, 1 hour, 2 hours). Western blotting analysis of total proteins $(60 \mu \mathrm{g})$ was carried out by PTPRJ (R\&D System) and CD98hc (Cell Signaling Technology) antibodies. Bona fide protein degradation was assayed by means of Pdcd4 (Santa Cruz) protein stability, as positive control. Equal loading was verified by tubulin (Sigma) and HDAC (Sigma).

\section{Quantitative real time PCR}

A549 cells were seeded in $100 \mathrm{~mm}$ culture dishes and, after 24 hours, transduced by a recombinant Adenovirus carrying a PTPRJ cDNA at a MOI50. RNA extraction was carried out with miRNeasy Mini Kit ${ }^{\mathrm{TM}}$ (Qiagen, Valencia, CA, USA), following the manufacturer's instructions, and total RNA was quantified with a spectrophotometer. Total RNA samples (250 ng) were retro-transcripted using the High Capacity RNAto-cDNA Kit (Applied Biosystems, Foster City, CA, USA), following the manufacturer's instructions. Five hundred nanolitres of cDNAs were amplified by realtime PCR with Promega SYBR green kit and 5 pmol of primers in a total volume of $25 \mu \mathrm{L}$. The primers used were: 5'-TCCCAGAATGCCGAGATGAT-3' (forward to 
SLC3A2), 5'-GCTCCACCTCCTTCATATCC-3' (reverse to $S L C 3 A 2)$, 5'-GTATTATCATTGGTGGCTTGTTC-3' (forward to PTPRJ), 5'-CATCTCCGTGGTGGTGAC-3' (reverse to PTPRJ) and 5'-AGGCAGGTGTTCAAATCAT CC-3' (reverse for short form of PTPRJ). Real-time PCRs were performed in a BioRad $\mathrm{iQ}^{\mathrm{TM}} 5$ tool in the following conditions: initial denaturation step at $95^{\circ} \mathrm{C}$ for $3 \mathrm{~min}$, followed by 40 cycles of $10 \mathrm{~s}$ at $95^{\circ} \mathrm{C}$ and $1 \mathrm{~min}$ at $57^{\circ} \mathrm{C}$. Specificity of PCR products was checked by melting curve analysis and gel electrophoresis. Values were normalized to HPRT RNA levels, ${ }^{*} P<0.05$.

\section{Cell survival assay}

$1 \times 10^{4}$ A549 cells were seeded in 96-well plates; cells were first transfected with 5 pmol of siCD98hc and six hours later transduced with Ad PTPRJ at MOI50. Cell proliferation was measured out twenty-four, forty-eight, and seventy-two hours after treatment through CellTiterGlo Luminescent Cell Viability assay (Promega) following the manufacture's protocols. The results were expressed as percent variation in the number of viable cells treated with CD98hc siRNA plus Ad PTPRJ compared with control Ad GFP plus scrambled siRNA treated cells.

\section{Clonogenic assay}

Briefly, $5 \times 10^{5}$ A549 cells were seeded per well in a 6-well plate. The next day cells were transfected with CD98hc siRNA (100 pmol) and six hours later transduced with Ad PTPRJ at MOI50, and incubated overnight. Following incubation, cells were harvested by trypsinization and counted; 300 cells then were seeded in 6 -well plate and were incubated at $37^{\circ} \mathrm{C}$. Twelve days later, the medium was removed and colonies were fixed and stained with cristal violet. Colony counting was performed by three different investigators.

\section{Wound-healing assay}

To examine cell migration, $3.5 \times 10^{5}$ A549 cells were seeded in a 6-well plate; the following day, cells were transfected with 100 pmol of CD98hc siRNA and infected with Ad PTPRJ at MOI50; twenty-four hours later, cell layer in the dishes was scratched using $200 \mu \mathrm{l}$ plastic pipette tips as previously described [59]. The closure of wounded area was measured six, twenty-four and forty-eight hours later by using a motorized inverted fluorescent microscope coupled with an high-sensitivity EM-CCD camera (Leica). The same experiment was performed in serum free conditions.

\section{Apoptosis assay}

A549 cells were cultured in 6-well plates; the day after, cells were transfected with 100 pmol of CD98hc
siRNA and six hours later transduced with $\operatorname{Ad} P T P R J$ at MOI20; twenty-four, forty-eight, and seventy-two hours later cells were analyzed by flow cytometry. Apoptosis was evaluated by FACS analysis following Annexin/V7AAD staining (BD Pharmigen). Annexin $\mathrm{V}^{+} / \mathrm{PI}^{-}$cells meant early apoptotic cells while Annexin $\mathrm{V}^{+} / \mathrm{PI}^{+}$cells meant late apoptotic cells.

\section{Statistical analysis}

Graphical analysis was performed by using GraphPad Software Prism 5. One-way analysis of variance (ANOVA) test, followed by Bonferroni post-test (for multiple comparisons), was used to detect the statistical significance. Differences in the results were considered significant with $p$-values $<0.05$. Statistical analysis for proteomic data was previously described in the section "Identification of PTPRJ-binding proteins by mass spectrometric analysis".

\section{ACKNOWLEDGMENTS}

This paper is dedicated to the loving memory of Dr. Eleonora Infante, a brilliant and beloved teacher, who prematurely died because of cancer on July 29, 2017. The authors also remember Prof. Salvatore Venuta, founder and first Chancellor of the University of Catanzaro, on the 10th anniversary of his premature passing. The present study was entirely supported by a generous donation by the Stillitani family, in loving memory of Carmelo, through the Fondazione Università Magna Groecia (FUMG) of Catanzaro. The authors are grateful to Dr. Luisa Infante for her precious support in the manuscript editing.

\section{CONFLICTS OF INTEREST}

None.

\section{REFERENCES}

1. Keane MM, Lowrey GA, Ettenberg SA, Dayton MA, Lipkowitz S. The protein tyrosine phosphatase DEP-1 is induced during differentiation and inhibits growth of breast cancer cells. Cancer Res. 1996; 56:4236-43.

2. Zhang L, Martelli ML, Battaglia C, Trapasso F, Tramontano D, Viglietto G, Porcellini A, Santoro M, Fusco A. Thyroid cell transformation inhibits the expression of a novel rat protein tyrosine phosphatase. Exp Cell Res. 1997; 235:62-70.

3. Trapasso F, Iuliano R, Boccia A, Stella A, Visconti R, Bruni P, Baldassarre G, Santoro M, Viglietto G, Fusco A. Rat protein tyrosine phosphatase eta suppresses the neoplastic phenotype of retrovirally transformed thyroid cells through 
the stabilization of p27(Kip1). Mol Cell Biol. 2000; 20:9236-46.

4. Cuozzo C, Porcellini A, Angrisano T, Morano A, Lee B, Di Pardo A, Messina S, Iuliano R, Fusco A, Santillo MR, Muller MT, Chiariotti L, Gottesman ME, Avvedimento EV. DNA damage, homology-directed repair, and DNA methylation. PLoS Genet. 2007; 3:e110.

5. Ruivenkamp CA, van Wezel T, Zanon C, Stassen AP, Vlcek C, Csikós T, Klous AM, Tripodis N, Perrakis A, Boerrigter L, Groot PC, Lindeman J, Mooi WJ, et al. Ptprj is a candidate for the mouse colon-cancer susceptibility locus $\mathrm{Scc} 1$ and is frequently deleted in human cancers. Nat Genet. 2002; 31:295-300.

6. Ruivenkamp C, Hermsen M, Postma C, Klous A, Baak J, Meijer G, Demant P. LOH of PTPRJ occurs early in colorectal cancer and is associated with chromosomal loss of 18q12-21. Oncogene. 2003; 22:3472-74.

7. Iuliano R, Le Pera I, Cristofaro C, Baudi F, Arturi F, Pallante P, Martelli ML, Trapasso F, Chiariotti L, Fusco A. The tyrosine phosphatase PTPRJ/DEP-1 genotype affects thyroid carcinogenesis. Oncogene. 2004; 23:8432-38.

8. Paduano F, Dattilo V, Narciso D, Bilotta A, Gaudio E, Menniti M, Agosti V, Palmieri C, Perrotti N, Fusco A, Trapasso F, Iuliano R. Protein tyrosine phosphatase PTPRJ is negatively regulated by microRNA-328. FEBS J. 2013; 280:401-12.

9. Luo X, Yang S, Zhou C, Pan F, Li Q, Ma S. MicroRNA-328 enhances cellular motility through posttranscriptional regulation of PTPRJ in human hepatocellular carcinoma. Onco Targets Ther. 2015; 8:3159-67.

10. Trapasso F, Drusco A, Costinean S, Alder H, Aqeilan RI, Iuliano R, Gaudio E, Raso C, Zanesi N, Croce CM, Fusco A. Genetic Ablation of Ptprj, a Mouse Cancer Susceptibility Gene, Results in Normal Growth and Development and Does Not Predispose to Spontaneous Tumorigenesis. DNA Cell Biol. 2006; 25:376-82.

11. Iuliano R, Trapasso F, Le Pera I, Schepis F, Samà I, Clodomiro A, Dumon KR, Santoro M, Chiariotti L, Viglietto G, Fusco A. An adenovirus carrying the rat protein tyrosine phosphatase eta suppresses the growth of human thyroid carcinoma cell lines in vitro and in vivo. Cancer Res. 2003; 63:882-86.

12. Trapasso F, Yendamuri S, Dumon KR, Iuliano R, Cesari R, Feig B, Seto R, Infante L, Ishii H, Vecchione A, During MJ, Croce CM, Fusco A. Restoration of receptor-type protein tyrosine phosphatase eta function inhibits human pancreatic carcinoma cell growth in vitro and in vivo. Carcinogenesis. 2004; 25:2107-14.

13. Takahashi T, Takahashi K, Mernaugh RL, Tsuboi N, Liu H, Daniel TO. A monoclonal antibody against CD148, a receptor-like tyrosine phosphatase, inhibits endothelial-cell growth and angiogenesis. Blood. 2006; 108:1234-42.

14. Paduano F, Ortuso F, Campiglia P, Raso C, Iaccino E, Gaspari M, Gaudio E, Mangone G, Carotenuto A, Bilotta
A, Narciso D, Palmieri C, Agosti V, et al. Isolation and functional characterization of peptide agonists of PTPRJ, a tyrosine phosphatase receptor endowed with tumor suppressor activity. ACS Chem Biol. 2012; 7:1666-76.

15. Ortuso F, Paduano F, Carotenuto A, Gomez-Monterrey I, Bilotta A, Gaudio E, Sala M, Artese A, Vernieri E, Dattilo V, Iuliano R, Brancaccio D, Bertamino A, et al. Discovery of PTPRJ agonist peptides that effectively inhibit in vitro cancer cell proliferation and tube formation. ACS Chem Biol. 2013; 8:1497-506.

16. Whiteford JR, Xian X, Chaussade C, Vanhaesebroeck B, Nourshargh S, Couchman JR. Syndecan-2 is a novel ligand for the protein tyrosine phosphatase receptor CD148. Mol Biol Cell. 2011; 22:3609-24.

17. Takahashi K, Mernaugh RL, Friedman DB, Weller R, Tsuboi N, Yamashita H, Quaranta V, Takahashi T. Thrombospondin-1 acts as a ligand for CD148 tyrosine phosphatase. Proc Natl Acad Sci USA. 2012; 109:1985-90.

18. Kovalenko M, Denner K, Sandström J, Persson C, Gross S, Jandt E, Vilella R, Böhmer F, Ostman A. Site-selective dephosphorylation of the platelet-derived growth factor beta-receptor by the receptor-like protein-tyrosine phosphatase DEP-1. J Biol Chem. 2000; 275:16219-26.

19. Palka HL, Park M, Tonks NK. Hepatocyte growth factor receptor tyrosine kinase met is a substrate of the receptor protein-tyrosine phosphatase DEP-1. J Biol Chem. 2003; 278:5728-35.

20. Iervolino A, Iuliano R, Trapasso F, Viglietto G, Melillo RM, Carlomagno F, Santoro M, Fusco A. The receptor-type protein tyrosine phosphatase $\mathrm{J}$ antagonizes the biochemical and biological effects of RET-derived oncoproteins. Cancer Res. 2006; 66:6280-87.

21. Berset TA, Hoier EF, Hajnal A. The C. elegans homolog of the mammalian tumor suppressor Dep-1/Scc1 inhibits EGFR signaling to regulate binary cell fate decisions. Genes Dev. 2005; 19:1328-40.

22. Grazia Lampugnani M, Zanetti A, Corada M, Takahashi T, Balconi G, Breviario F, Orsenigo F, Cattelino A, Kemler R, Daniel TO, Dejana E. Contact inhibition of VEGFinduced proliferation requires vascular endothelial cadherin, $\beta$-catenin, and the phosphatase DEP-1/CD148. J Cell Biol. 2003; 161:793-804.

23. Sacco F, Tinti M, Palma A, Ferrari E, Nardozza AP, Hooft van Huijsduijnen R, Takahashi T, Castagnoli L, Cesareni G. Tumor suppressor density-enhanced phosphatase-1 (DEP-1) inhibits the RAS pathway by direct dephosphorylation of ERK1/2 kinases. J Biol Chem. 2009; 284:22048-58.

24. Verrey F, Jack DL, Paulsen IT, Saier MH Jr, Pfeiffer R. New glycoprotein-associated amino acid transporters. J Membr Biol. 1999; 172:181-92.

25. Tsumura H, Suzuki N, Saito H, Kawano M, Otake S, Kozuka Y, Komada H, Tsurudome M, Ito Y. The targeted disruption of the CD98 gene results in embryonic lethality. Biochem Biophys Res Commun. 2003; 308:847-51. 
26. Nguyen HT, Dalmasso G, Torkvist L, Halfvarson J, Yan Y, Laroui H, Shmerling D, Tallone T, D'Amato M, Sitaraman SV, Merlin D. CD98 expression modulates intestinal homeostasis, inflammation, and colitis-associated cancer in mice. J Clin Invest. 2011; 121:1733-47.

27. Esseghir S, Reis-Filho JS, Kennedy A, James M, O'Hare MJ, Jeffery R, Poulsom R, Isacke CM. Identification of transmembrane proteins as potential prognostic markers and therapeutic targets in breast cancer by a screen for signal sequence encoding transcripts. J Pathol. 2006; 210:420-30.

28. Kaira K, Ohde Y, Endo M, Nakagawa K, Okumura T, Takahashi T, Murakami H, Tsuya A, Nakamura Y, Naito T, Kondo H, Nakajima T, Yamamoto N. Expression of 4F2ho (CD98) in pulmonary neuroendocrine tumors. Oncol Rep. 2011; 26:931-37.

29. Fuchs BC, Bode BP. Amino acid transporters ASCT2 and LAT1 in cancer: partners in crime? Semin Cancer Biol. 2005; 15:254-66

30. Bulus N, Feral C, Pozzi A, Zent R. CD98 increases renal epithelial cell proliferation by activating MAPKs. PLoS One. 2012; 7:e40026.

31. Prager GW, Féral CC, Kim C, Han J, Ginsberg MH. CD98hc (SLC3A2) interaction with the integrin beta subunit cytoplasmic domain mediates adhesive signaling. J Biol Chem. 2007; 282:24477-84.

32. Henderson NC, Collis EA, Mackinnon AC, Simpson KJ, Haslett C, Zent R, Ginsberg M, Sethi T. CD98hc (SLC3A2) interaction with beta 1 integrins is required for transformation. J Biol Chem. 2004; 279:54731-41.

33. Feral CC, Nishiya N, Fenczik CA, Stuhlmann H, Slepak M, Ginsberg MH. CD98hc (SLC3A2) mediates integrin signaling. Proc Natl Acad Sci USA. 2005; 102:355-60.

34. Sams-Dodd F. Target-based drug discovery: is something wrong? Drug Discov Today. 2005; 10:139-47.

35. He RJ, Yu ZH, Zhang RY, Zhang ZY. Protein tyrosine phosphatases as potential therapeutic targets. Acta Pharmacol Sin. 2014; 35:1227-46.

36. Tonks NK. Protein tyrosine phosphatases: from genes, to function, to disease. Nat Rev Mol Cell Biol. 2006; 7:833-46.

37. Julien SG, Dubé N, Hardy S, Tremblay ML. Inside the human cancer tyrosine phosphatome. Nat Rev Cancer. 2011; 11:35-49.

38. Tonks NK. Protein tyrosine phosphatases-from housekeeping enzymes to master regulators of signal transduction. FEBS J. 2013; 280:346-78.

39. Lee H, Yi JS, Lawan A, Min K, Bennett AM. Mining the function of protein tyrosine phosphatases in health and disease. Semin Cell Dev Biol. 2015; 37:66-72.

40. Rhee I, Veillette A. Protein tyrosine phosphatases in lymphocyte activation and autoimmunity. Nat Immunol. 2012; 13:439-47.
41. Fenczik CA, Zent R, Dellos M, Calderwood DA, Satriano J, Kelly C, Ginsberg MH. Distinct domains of CD98hc regulate integrins and amino acid transport. J Biol Chem. $2001 ; 276: 8746-52$.

42. Kaira K, Nakamura K, Hirakawa T, Imai H, Tominaga H, Oriuchi N, Nagamori S, Kanai Y, Tsukamoto N, Oyama T, Asao T, Minegishi T. Prognostic significance of L-type amino acid transporter 1 (LAT1) expression in patients with ovarian tumors. Am J Transl Res. 2015; 7:1161-71.

43. Kaira K, Oriuchi N, Imai H, Shimizu K, Yanagitani N, Sunaga N, Hisada T, Kawashima O, Iijima H, Ishizuka T, Kanai Y, Endou H, Nakajima T, Mori M. Expression of L-type amino acid transporter 1 (LAT1) in neuroendocrine tumors of the lung. Pathol Res Pract. 2008; 204:553-61.

44. Oxender DL, Christensen HN. Evidence for two types of mediation of neutral and amino-acid transport in Ehrlich cells. Nature. 1963; 197:765-67.

45. Nawashiro H, Otani N, Shinomiya N, Fukui S, Ooigawa H, Shima K, Matsuo H, Kanai Y, Endou H. L-type amino acid transporter 1 as a potential molecular target in human astrocytic tumors. Int J Cancer. 2006; 119:484-92.

46. Kaira K, Oriuchi N, Imai H, Shimizu K, Yanagitani N, Sunaga N, Hisada T, Tanaka S, Ishizuka T, Kanai Y, Endou H, Nakajima T, Mori M. 1-type amino acid transporter 1 and CD98 expression in primary and metastatic sites of human neoplasms. Cancer Sci. 2008; 99:2380-86.

47. Napolitano L, Scalise M, Galluccio M, Pochini L, Albanese LM, Indiveri C. LAT1 is the transport competent unit of the LAT1/CD98 heterodimeric amino acid transporter. Int J Biochem Cell Biol. 2015; 67:25-33.

48. Cromm PM, Crews CM. Targeted Protein Degradation: from Chemical Biology to Drug Discovery. Cell Chem Biol. 2017; 24:1181-90.

49. Talarico C, Dattilo V, D'Antona L, Menniti M, Bianco C, Ortuso F, Alcaro S, Schenone S, Perrotti N, Amato R. SGK1, the New Player in the Game of Resistance: ChemoRadio Molecular Target and Strategy for Inhibition. Cell Physiol Biochem. 2016; 39:1863-76.

50. Ortuso F, Amato R, Artese A, D'antona L, Costa G, Talarico C, Gigliotti F, Bianco C, Trapasso F, Schenone S, Musumeci F, Botta L, Perrotti N, et al. In Silico Identification and Biological Evaluation of Novel Selective Serum/Glucocorticoid-Inducible Kinase 1 Inhibitors Based on the Pyrazolo-Pyrimidine Scaffold. J Chem Inf Model. 2014; 54:1828-32.

51. Hayes GM, Chinn L, Cantor JM, Cairns B, Levashova Z, Tran H, Velilla T, Duey D, Lippincott J, Zachwieja J, Ginsberg MH, van der Horst EH. Antitumor activity of an anti-CD98 antibody. Int J Cancer. 2015; 137:710-20.

52. $\mathrm{Xu} \mathrm{D}$, Hemler ME. Metabolic activation-related CD147-CD98 complex. Mol Cell Proteomics. 2005; $4: 1061-71$.

53. Santiago-Gómez A, Barrasa JI, Olmo N, Lecona E, Burghardt H, Palacín M, Lizarbe MA, Turnay J. 
4F2hc-silencing impairs tumorigenicity of HeLa cells via modulation of galectin-3 and $\beta$-catenin signaling, and MMP-2 expression. Biochim Biophys Acta. 2013; 1833:2045-56.

54. Hanahan D, Weinberg RA. Hallmarks of cancer: the next generation. Cell. 2011; 144:646-74.

55. Varano M, Gaspari M, Quirino A, Cuda G, Liberto $\mathrm{MC}$, Focà $\mathrm{A}$. Temperature-dependent regulation of the Ochrobactrum anthropi proteome. Proteomics. 2016; 16:3019-24.

56. Chen D, Shah A, Nguyen H, Loo D, Inder KL, Hill MM. Online Quantitative Proteomics p-Value Calculator for Permutation-Based Statistical Testing of Peptide Ratios. J Proteome Res. 2014; 13:4184-91.

57. Szklarczyk D, Morris JH, Cook H, Kuhn M, Wyder S, Simonovic M, Santos A, Doncheva NT, Roth A, Bork P,
Jensen LJ. Von Mering C. The STRING database in 2017: quality-controlled protein-protein association networks, made broadly accessible. Nucleic Acids Res. 2017; 45:D362-8.

58. Costa V, Foti D, Paonessa F, Chiefari E, Palaia L, Brunetti G, Gulletta E, Fusco A, Brunetti A. The insulin receptor: a new anticancer target for peroxisome proliferator-activated receptor-gamma (PPARgamma) and thiazolidinedionePPARgamma agonists. Endocr Relat Cancer. 2008; $15: 325-35$.

59. Bilotta A, Dattilo V, D'Agostino S, Belviso S, Scalise S, Bilotta M, Gaudio E, Paduano F, Perrotti N, Florio T, Fusco A, Iuliano R, Trapasso F, et al. A novel splice variant of the protein tyrosine phosphatase PTPRJ that encodes for a soluble protein involved in angiogenesis. Oncotarget. 2017; 8:10091-10102. https://doi.org/10.18632/oncotarget.14350. 